\title{
Data Envelopment Analysis (DEA) for evacuation planning
}

\author{
F. Russo \& C. Rindone \\ Mediterranea University of Reggio Calabria, Italy
}

\begin{abstract}
In this paper a non parametric method to evaluate evacuation planning in an urban system is presented. An efficiency criterion is adopted and Data Envelopment Analysis, in the field of non parametric methods, is proposed to compare different evacuation plans. A test application is illustrated.
\end{abstract}

Keywords: evacuation planning, evaluation methods, efficiency, Data Envelopment Analysis.

\section{Introduction}

Evacuation planning allows one to analyse the exposure component of risk and works to prepare and to implement activities to reduce risk. Risk has three main components: probability (or frequency) that the event occurs; vulnerability, which is related only to the resistance of the infrastructures when the event occurs; exposure, which is an equivalent homogeneous weighted value of people, goods and infrastructures affected during and after the event. In the following, the exposure component is considered. The main measure to reduce exposure is evacuation, which consists of reducing the number of users and goods that can experience negative effects when emergency events occur [1].

An evacuation is a complex process that depends on numerous factors. Human factors play a relevant role in evacuation [2]. A generic evacuation plan can be characterised from different elements: resources involved, strategies implemented, objectives pursued. The plan, in some cases, is not ever tested in reality. Several factors can influence evacuation procedures, but some of these are not ever modelled.

In recent years different tools (specific but non integrated simulation models; Decision Support System; real experimentations) have been available to support 
decision makers in preparing evacuation plans (see [3-6] and literature inside reported).

Evacuation planning requires two different steps of analysis:

- estimation models to reproduce transport system in emergency condition;

- evaluation methods to compare alternative evacuation plans.

In the first step, two different approaches to estimate an evacuation plan can be adopted:

- a first approach is to apply simulation models of mobility in emergency condition (simulation approach);

- a second approach is to realise real experimentations (or exercises) of an evacuation, finalised to reproduce in the reality mobility in evacuation conditions (exercise approach).

Each approach allows us to obtain data (simulated or observed) about evacuation process [7].

In the SICURO research project, developed by LAST (Laboratory for Transport Systems Analysis), a system of models to simulate evacuation process is developed. The system of models is organised in: demand models with SP evolutions [8-12]; simulation models of transport supply to represent performances of infrastructure and services in evacuation condition and supplydemand interaction, to estimate vehicle evacuation times to reach refuge areas [13-17]; design of path choice models for emergency vehicles, to estimate times to evacuate weak users and pupils [18-22]; simulation models of the refuge area for users, to estimate access times [23].

In the second step, evaluation methods for planning, allow us to compare effects of different plans respect to one or more criteria. Single elements of an evacuation plan can be evaluated by means of specific indicators. Based on these indicators, different evacuation plans can be compared in ex ante and in ex post conditions. However, the direct analysis, of the estimated indicators, can give opposite results. For this reason it is necessary to apply different classes of evaluation methods that, considering contemporaneously all indicators, give an unifying evaluation result.

Estimation models and evaluation methods for evacuation planning have some limitations. Some real factors, that could influence transport system in emergency conditions, cannot be reproduced by means of simulation or exercise approach.

In this paper, an evaluation method, based on efficiency criterion, is proposed. The method is based on the assumption that an evacuation is represented by means of a production process fed by a set of inputs that are combined to obtain a set of one or more outputs. Performances of this process are measured in terms of efficiency. Efficiency of the production process is adopted how criterion to compare evacuation processes.

In literature several methods to measure efficiency are available. A possible classification of these methods is based on the production function [24]:

- non-parametric methods, based on the assumption that the production function of fully efficient firms is not known; 
- $\quad$ parametric methods, based on the assumption that the production function of fully efficient firms is known.

In this paper, considering complexity of evacuation process, non-parametric methods to evaluate efficiency are adopted. A Data Envelopment Analysis (DEA) method, to evaluate evacuation planning process of an urban system in emergency conditions, is applied.

After this introduction, the paper has three sections. In section 2, DEA in transportation planning is presented. In section 3, DEA for evacuation planning is proposed. In section 4, an exemplification of DEA approach for evacuation planning is illustrated.

\section{DEA for transport planning}

\subsection{Literature review}

Starting from Farrell's definition of efficiency [25], the first formulation of DEA was introduced by Charnes et al. [26], and indicated with the acronym CCR referring to author's names. This formulation was based on the hypothesis of Constant Returns to Scale (CRS). An extension of the CCR model, denoted with the acronym BCC, has been proposed by Banker et al. [27], in which the CRS hypothesis is removed and Variable Returns to Scale (VRS) (decreasing or increasing) are admitted.

DEA is based on technical efficiency concept that measures capacity of a decision unit (or in general Decision Making Unit - DMU) to realize a productive process that combine production factors (input) to obtain a product (output). Then, each DMU is represented by means of a set of one, or more, inputs and a set of one, or more, outputs.

Defining the space of input variables $\left(\mathrm{R}^{\mathrm{r}}\right)$ and output variables $\left(\mathrm{R}^{\mathrm{s}}\right)$, each DMU can be allocated in the point representative of her efficiency belonging to the space $\mathrm{R}^{(\mathrm{r} U \mathrm{~s})}$.

Efficient DMU belong to the frontier. The distance from this frontier is a measure of inefficiency of a DMU, which could be eliminated through a variation in quantity of inputs (input-oriented) or outputs (output-oriented) or both (additive model) [28].

DEA was originally introduced to evaluate production efficiency in industrial systems, where inputs are labour, energy and capital resources and outputs are goods or services. DEA has subsequently been applied in many fields of economics and engineering [29]. Few DEA applications focus on transport services, especially to evaluate performance of urban transport $[30,31]$, container ports [32] and airports [33]. In some papers DEA is applied within an evaluation process in order to rank different alternative scenarios [34-37]. Variation on time of efficiency measures is considered in different approach. Commonly approaches presented on literature are: contemporaneous approach; intertemporal approach; sequential approach; windows analysis [38, 39]. These approaches differ on construction of observation set into different temporal periods. 


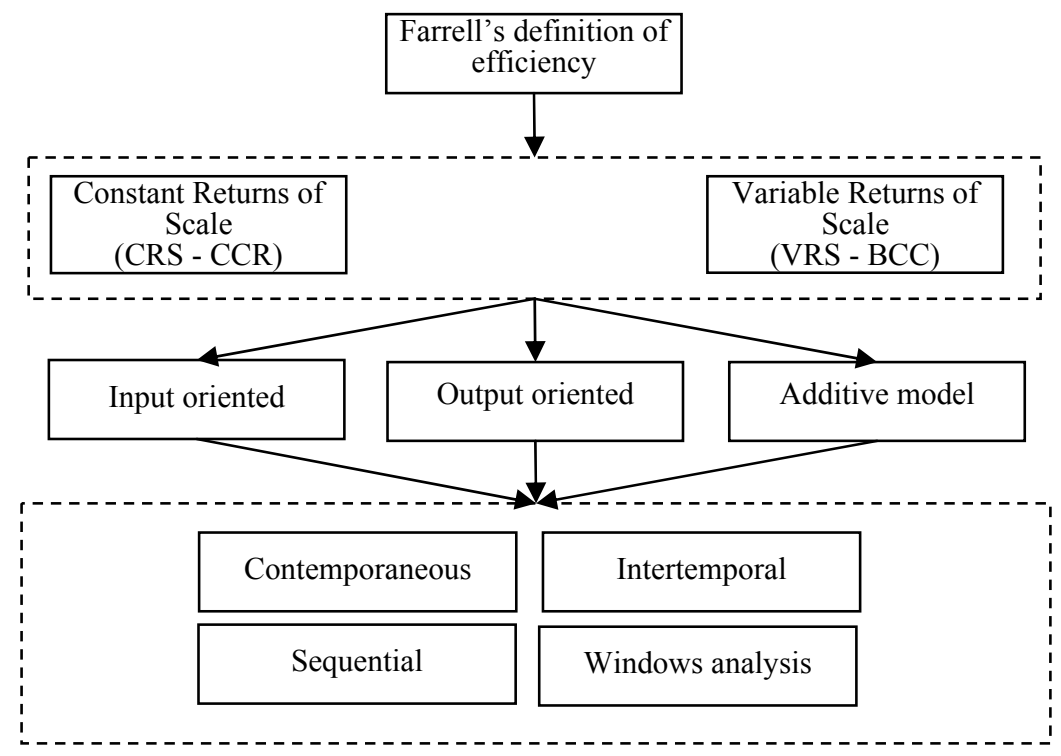

Figure 1: Classification of DEA methods.

A possible classification of DEA methods is presented in Figure 1.

\subsection{Analytic formulation}

A transport plan (or each alternative scenario that must be compared of the same plan) is represented how a process. Each process can be represented by means of:

- $\quad$ a set of input variables (that can be aggregate in a virtual input);

- a set of output variables (that can be aggregate in a virtual output).

The efficiency criterion is specified in different forms available in literature.

Comparisons among planning processes are made without using any hypothesis on relationships among inputs and outputs.

Given socioeconomic characteristics of the area interested by transportation planning (population, land characteristics ...), inputs comprehend needed resources to realize interventions (activities) for the plan implementation. It is necessary to define temporal and financial specification of resources. Inputs can be hypothesised and introduced in simulation models or measured if really used.

Activities allow one to modify elements of transport system following planner's decisions: material and immaterial infrastructures; managerial elements; equipment; normative elements.

Outputs comprehend all variables that result from the planning process. In transportation planning, outputs include tangible products (e.g. infrastructures) and intangible products (e.g. services) resulting from planned activities. Outputs can be estimated adopting simulation models or measured by monitoring. 


\subsubsection{Input variables}

In analytical terms, the $\mathrm{j}^{\text {th }}$ transportation plan, $\mathrm{j}=1, \ldots, \mathrm{n}$, is represented by a vector of inputs $\mathbf{i}_{\mathrm{j}}$ of $\mathrm{r}$ dimension, where $\mathrm{r}$ is the number of the inputs considered in the plan; this vector corresponds to multi-input attributes selected to represent a generic process:

$$
\mathbf{i}_{\mathrm{j}}:\left(\mathrm{i}_{1}, \mathrm{i}_{2}, \ldots, \mathrm{i}_{\mathrm{r}}\right)^{\mathrm{T}} \in \mathrm{R}^{\mathrm{r}} \quad(\mathrm{j}=1, \ldots, \mathrm{n})
$$

All plans can be represented contemporaneously with a matrix I with $\mathrm{n} \cdot \mathrm{r}$ dimensions, where $\mathrm{n}$ is the number of plans considered and $\mathrm{r}$ is the number of inputs considered in the virtual process for each plan.

For each process it is possible to obtain a homogeneous measure of input (virtual input) introducing unknown weights for each component of inputs. At $\mathrm{j}^{\text {th }}$ process is associated a vector of unknown weights assigned to inputs of $r$ dimension; this vector corresponds to multi-input parameters selected to represent a generic process:

$$
\mathbf{v}_{\mathrm{j}}:\left(\mathrm{v}_{1}, \ldots, \mathrm{v}_{\mathrm{r}}\right)^{\mathrm{T}} \quad(\mathrm{j}=1, \ldots, \mathrm{n})
$$

The measure of virtual input for $\mathrm{j}^{\text {th }}$ process is:

$$
\mathrm{I}_{\mathrm{j}}=\mathbf{v}_{\mathrm{j}}^{\mathrm{T}} \mathbf{i}_{\mathrm{j}} \quad(\mathrm{j}=1, \ldots, \mathrm{n})
$$

\subsubsection{Output variables}

In analytical terms, each transport plan $(j=1, \ldots, n)$ is represented by a vector of outputs $\mathbf{0}_{\mathrm{j}}$ of $\mathrm{s}$ dimensions, where $\mathrm{s}$ is the number of the outputs considered in the virtual plan; this vector corresponds to multi-output attributes selected to represent a generic virtual process:

$$
\mathbf{o}_{\mathrm{j}}:\left(\mathrm{o}_{\mathrm{i}}, \mathrm{o}_{2}, \ldots, \mathrm{o}_{\mathrm{s}}\right)^{\mathbf{T}} \in \mathrm{R}^{\mathrm{s}} \quad(\mathrm{j}=1, \ldots, \mathrm{n})
$$

All transport plans can be represented contemporaneously with a matrix $\mathbf{O}$ with $\mathrm{n} \cdot \mathrm{s}$ dimensions, where $\mathrm{n}$ is the number of plans considered and $\mathrm{s}$ is the number of outputs considered in the virtual process.

For each process it is possible to obtain a homogeneous measure of output (virtual output) introducing unknown weights for each component of outputs. At $\mathrm{j}^{\text {th }}$ plan is associated a vector of unknown weights assigned to inputs of $\mathrm{s}$ dimensions; this vector corresponds to multi-output parameters selected to represent a generic process:

$$
\mathbf{u}_{\mathrm{j}}:\left(\mathrm{u}_{1}, \ldots, \mathrm{u}_{\mathrm{s}}\right)^{\mathrm{T}} \quad(\mathrm{j}=1, \ldots, \mathrm{n})
$$

The measure of virtual output for $\mathrm{j}^{\text {th }}$ process is:

$$
\mathrm{O}_{\mathrm{j}}=\mathbf{u}_{\mathrm{j}}^{\mathrm{T}} \mathbf{o}_{\mathrm{j}} \quad(\mathrm{j}=1, \ldots, \mathrm{n})
$$

\subsubsection{Efficiency criterion specification}

The analytic formulation of DEA is based on a measure of efficiency $\left(\theta_{j}\right)$ of $j^{\text {th }}$ evacuation process in terms of ratio between virtual output and virtual input: 


$$
\theta_{\mathrm{j}}=\mathrm{O}_{\mathrm{j}} / \mathrm{I}_{\mathrm{j}} \quad(\mathrm{j}=1, \ldots, \mathrm{n})
$$

For definition, the CCR form of efficiency measurement problems can be written as a set of $\mathrm{n}$ linear programming problems to obtain unknown weights assigned to inputs and outputs. If the goal is pursued for increasing values of output, it follow that objective function have to be maximized; otherwise, objective function, have to be minimized.

In the maximizing form the $\mathrm{j}^{\text {th }}$ problem is expressed:

$$
\begin{array}{ll}
\operatorname{maximize} \theta_{j}=\mathrm{O}_{\mathrm{j}} / \mathrm{I}_{\mathrm{j}} & (\mathrm{j}=1, \ldots, \mathrm{n}) \\
\mathbf{u}_{\mathrm{j}}, \mathbf{v}_{\mathbf{j}} & \\
\text { subject to: } & (\mathrm{j}=1, \ldots, \mathrm{n}) \\
\mathrm{O}_{\mathrm{j}} / \mathrm{I}_{\mathrm{j}} \leq 1 & \\
\mathbf{u}_{\mathrm{j}} \geq 0 & \\
\mathbf{v}_{\mathrm{j}} \geq 0 &
\end{array}
$$

This formulation, for each $\mathrm{j}^{\text {th }}$ evacuation process, can be used to find the set of weights, $\mathbf{u}_{\mathrm{j}}$ and $\mathbf{v}_{\mathrm{j}}$, that maximize the efficiency indicator, $\theta_{\mathrm{j}}$, assuming that the maximum value is equal to one.

The efficient frontier is obtained from envelopment of points representing efficient planning process. Points not belonging to the frontier represent nonefficient processes. Among the considered processes, there is at least one that is efficient. For the inefficient points, the distance from the frontier may be calculated.

\section{DEA specification for evacuation planning}

In the following, an evacuation is represented by means of an evacuation (production) process, shortly named evacuation process.

DEA method is proposed to compare different evacuation processes.

Each evacuation process is represented by means of a set of input variables and a set of output variables.

\subsection{Input variables}

Selection of input variables depends on approach adopted to analyse evacuation process. If evacuation process is analysed adopting simulation approach, inputs can be selected from variables that fed simulation models. For instance, in this case, input variables can be the total amount of urban road network extension or the total amount of available surfaces for refuge area, or the average distance from refuge area. It can be considered input more complex in which the evacuating population is weighted by network characteristics (material and immaterial). If evacuation process is obtained adopting exercises approach, input can be selected from variables that are measured by means of monitoring tools. For instance, in this case, input variables can be characteristics of urban infrastructures monitored. 


\subsection{Output variables}

Outputs comprehend results of evacuation process. Outputs obtained from the process can be related to: direct results that measure the quantity of simulations and/or real exercises produced; intermediate results that measure the quality of evacuation plans produced for instance in terms of evacuation times estimated by simulation models or measured by monitoring tools.

Selection of output variables depends on approach adopted to analyse evacuation process. If evacuation process is analysed adopting simulation approach, outputs can be selected from variables resulting from simulation models. For instance, in this case, output variables can be evacuation times estimated adopting simulation models. If evacuation process is obtained adopting exercises approach, output can be selected from variables that are measured by means of monitoring models. For instance, in this case, output variables can be evacuation times measured adopting specific monitoring tools.

\subsection{Specification}

Specification of DEA method (CCR or BCC) depends on hypothesis about evacuation process.

Evacuation planning is finalised to improve performances of transport system in emergency conditions, assumed constant available resources. In particular the main goal of evacuation planning is to reduce risk. In this paper, following the definition of risk given in section 1, we consider exposure measured in terms of evacuation times. In this condition evacuation time have to be as low as possible. For this reason, DEA specification for evacuation process is assumed output oriented minimising output/input ratio.

Finally the problems (2) may be expressed in the following form:

$$
\begin{array}{ll}
\operatorname{minimize} \theta j=O j / I j & (j=1, \ldots, n) \\
\mathbf{u}_{\mathrm{j}}, \mathbf{v}_{\mathrm{j}} & \\
\text { subject to: } & (\mathrm{j}=1, \ldots, \mathrm{n}) \\
\mathrm{O}_{\mathrm{j}} / \mathrm{I}_{\mathrm{j}} \geq 1 & \\
\mathbf{u}_{\mathrm{j}} \geq 0 & \\
\mathbf{v}_{\mathrm{j}} \geq 0 &
\end{array}
$$

\section{Application}

The application has been developed to verify applicability of DEA method to compare different evacuation processes.

In the application, evacuation processes relative to different cities and towns, of the south of the Italy, are considered: Reggio Calabria, a city with an estimated population of 185.000 inhabitants and a population density of 0,78 inhabitants per square kilometres; Zafferana Etnea (CT) a town with an 
estimated population of 7.300 inhabitants and a population density of 0,12 inhabitants per square kilometres; Melito P.S. (RC) a town with an estimated population of 11.400 inhabitants and a population density of 0,20 inhabitants per square kilometres. The emergency event hypothesized is an accident that involves dangerous goods. For this event an evacuation is ordered. In all three cases, evacuation involves a limited area of urban centre. People use vehicle to evacuate. Three evacuation processes are compared (Table 1).

To exemplify, in the following we suppose that processes are characterised from only one input and only one output.

Specification is proposed according to CCR method, output oriented.

\subsection{Input variable}

Inputs variable comprehend a measure of socioeconomic characteristics of study area.

In particular in the application we consider the quantity of population that must to be evacuated by means of cars, and then we consider as indicator the number of vehicles to evacuate. Recalling the hypothesis given in section 3.1, we here consider that the three networks have same average characteristics, and then can be considered not influent for the solutions (Table 1).

\subsection{Output variable}

Output variable comprehend a measure of results produced from an evacuation process. In the application we consider evacuation times that have to decreasing when improving results of evacuation.

The scenarios simulated concerns an incident involving dangerous goods. The presence of a potentially disastrous event is announced. The mayor decides that the surrounding area must be evacuated. Times, to evacuate people that using vehicles, are referred to current situation not considering network design for improving evacuation procedures and they are estimated adopting models realised in SICURO project (Table 1). We define evacuation time the time that need to arrive in refuge area for all vehicles evacuated.

Table 1: $\quad$ Input and output variables.

\begin{tabular}{ccccccc}
\hline DMU & City/town & Surface & $\begin{array}{c}\text { Density } \\
\text { inhab. } \\
10^{3} / \\
\left.\mathrm{km}^{2}\right)\end{array}$ & $\begin{array}{c}\text { Population } \\
(\mathrm{inhab} . \\
\left.10^{3}\right)\end{array}$ & $\begin{array}{c}\text { Vehicles to } \\
\text { evacuate } \\
(\text { vehic. } \\
\left.10^{3}\right) \\
\left(\text { input, } \mathrm{i}_{\mathrm{j}}\right)\end{array}$ & $\begin{array}{c}\text { Evacuation } \\
\text { time } \\
\text { (hours) }\end{array}$ \\
\hline 1 & $\begin{array}{c}\text { Reggio Calabria } \\
\left(\text { output, } \mathrm{o}_{\mathrm{j}}\right)\end{array}$ \\
\hline 2 & 236 & 0,78 & 185,0 & 12,0 & 23,00 \\
3 & $\begin{array}{c}\text { Zafferana Etnea } \\
(\mathrm{CT})\end{array}$ & 76 & 0,12 & 7,3 & 2,0 & 0,6 \\
\hline
\end{tabular}




\subsection{Specification}

For each evacuation process, adopting specification (5) presented in section 3.3, a linear programming problem can be formulated:

DMU 1: Reggio Calabria DMU 2: Zafferana Etnea DMU 3: Melito P.S (RC)

\begin{tabular}{|c|c|c|}
\hline $\min _{\mathrm{u}_{1}, \mathrm{v}_{1}} \theta_{1}=23 \mathrm{u}_{1} / 12 \mathrm{v}_{1}$ & $\min _{\mathrm{u}_{2}, \mathrm{v}} \theta_{2}=0,6 \mathrm{u}_{2} / 2 \mathrm{v}_{2}$ & $\min _{\mathrm{u}_{3}, \mathrm{v}} \theta_{3}=0,35 \mathrm{u}_{3} / 0,2 \mathrm{v}$ \\
\hline subject to: & subject to: & subject to: \\
\hline $23 \mathrm{u}_{1} / 12 \mathrm{v}_{1} \geq 1$ & $23 \mathrm{u}_{2} / 12 \mathrm{v}_{2} \geq 1$ & $23 u_{3} / 12 v_{3} \geq 1$ \\
\hline $0,6 \mathrm{u}_{1} / 2,0 \mathrm{v}_{1} \geq 1$ & $0,6 \mathrm{u}_{2} / 2,0 \mathrm{v}_{2} \geq 1$ & $0,6 \mathrm{u}_{3} / 2,0 \mathrm{v}_{3} \geq 1$ \\
\hline $0,35 \mathrm{u}_{1} / 0,20 \mathrm{v}_{1} \geq 1$ & $0,35 \mathrm{u}_{2} / 0,20 \mathrm{v}_{2} \geq 1$ & $0,35 \mathrm{u}_{3} / 0,20 \mathrm{v}_{3} \geq 1$ \\
\hline $\mathrm{u}_{1} \geq 0$ & $\mathrm{u}_{2} \geq 0$ & $\mathrm{u}_{3} \geq 0$ \\
\hline $\mathrm{v}_{1} \geq 0$ & $\mathrm{v}_{2} \geq 0$ & $\mathrm{v}_{3} \geq 0$ \\
\hline
\end{tabular}

From the resolution of the three problems, CCR frontier and distances from them are obtained. From this resolution it is possible to obtain score efficiency to rank DMU.

Some prototypal results are reported in Table 2. Zafferana Etnea (CT) is only DMU efficient $\left(\theta_{2}=1\right)$. Melito P.S (RC) is not efficient $\left(\theta_{3}=5,83\right)$ but has a score efficiency higher than Reggio Calabria $\left(\theta_{1}=6,39\right)$.

We can note that the score of Zafferana Etnea depend on the network that is more extended than other DMUs and on the quantity and position of refuge area. In general results depend on the choice set of input and output variables selected to represent evacuation process. The case considered is simplified because one input and one output variables are selected.

\section{Conclusions}

Analysis to support evacuation planning comprehends estimation and evaluation steps to reproduce a specific plan and to compare different evacuation plans. To estimate an evacuation plan, two different approaches can be adopted; simulation approach and exercise approach. To evaluate an evacuation plan, parametric and

Table 2: $\quad$ Prototypal results.

\begin{tabular}{cccc}
\hline City & $\begin{array}{c}\text { Weighted input } \\
\left(\mathrm{v}_{\mathrm{j}} \mathrm{i}_{\mathrm{j}}\right)\end{array}$ & $\begin{array}{c}\text { Weighted output } \\
\left(\mathrm{u}_{\mathrm{j}} \mathrm{o}_{\mathrm{j}}\right)\end{array}$ & $\begin{array}{c}\text { Score efficiency } \\
\left(\theta_{1}\right)\end{array}$ \\
\hline Reggio Calabria & 1,00 & 6,39 & 6,39 \\
Zafferana Etnea (CT) & 1,00 & 1,00 & 1,00 \\
Melito P.S (RC) & 1,00 & 5,83 & 5,83 \\
\hline
\end{tabular}


non-parametric methods can be adopted. Generally these methods were applied in economics to compare performances of different firms. Comparisons concerns firm's output in terms of services produced.

In this paper, an evaluation method for evacuation planning is proposed. The method is based on the assumption that an evacuation is represented by means of a production process fed by a set of inputs that are combined to obtain a set of one or more outputs. Performances of this process are measured in terms of efficiency.

A non-parametric method to compare different evacuation process in terms of efficiency is proposed. A Data Envelopment Analysis (DEA) method, to evaluate an urban system in emergency conditions, is applied.

Principal aim of this paper is to verify applicability of DEA to compare evacuation processes in urban transport systems in emergency conditions. A simplified application is presented in order to test the potential of DEA in evacuation planning.

Possible extensions of this work concern the choice of other inputs and output sets or the choice of evacuation (simulation or exercises) selected for comparisons.

\section{References}

[1] Russo F. \& Vitetta A., Risk evaluation in a transportation system. International Journal of Sustainable Development and Planning, 1 (2), pp. 170-191, 2006.

[2] Goldblatt, R., Evacuation planning. Human factor and traffic engineering perspectives. Proceedings of the European Transport Conference, Strasbourg, 2004

[3] Russo F. \& Vitetta A., Safety of users in road evacuation: General methodology and main results. Proc. of Urban Transport XIII, Urban Transport and the Environment in the 21st century, Brebbia C. A. (ed.), WIT Press, Southampton, pp. 763-772, 2007.

[4] Russo F. \& Rindone C., Safety of users in road evacuation: planning internal processes and guidelines. Proc. of Urban Transport XIII, Urban Transport and the Environment in the 21st century, Brebbia C. A. (ed.), WIT Press, Southampton, pp. 825-834, 2007.

[5] Russo F. \& Rindone C., Safety of users in road evacuation: Modelling and DSS for LFA in the planning process. Proc. of Sustainable Development and Planning IV, vol.1, Brebbia C. A. (ed.), WIT Press, Southampton, pp. 453-464, 2009.

[6] Russo F. \& Rindone C., Safety of users in road evacuation: the logical framework approach in evacuation planning. Proc. of Urban Transport $X I V$, Urban Transport and the Environment in the 21st century, Brebbia C. A. (ed.), WIT Press, Southampton, pp. 751-760, 2008.

[7] Russo F. \& Rindone C., Evaluation methods for evacuation planning. Proc. of Urban Transport XVI, Urban Transport and the Environment in the 21st century, Brebbia C. A. (ed.), WIT Press, Southampton, pp. 335-343, 2010. 
[8] Russo F. \& Chilà G., Safety of users in road evacuation: demand models. Proc. of Urban Transport XIII, Urban Transport and the Environment in the 21st century, Brebbia C. A. (ed.), WIT Press, Southampton, pp. 773$782,2007$.

[9] Russo F. \& Chilà G., Safety of users in road evacuation: RP vs. SP surveys in demand analysis. Proc. of Urban Transport XIV, Urban Transport and the Environment in the 21st century, Brebbia C. A. (ed.), WIT Press, Southampton, pp. 703-713, 2008.

[10] Russo F. \& Chilà G., Safety of users in road evacuation: Modelling and DSS for demand. Proc. of Sustainable Development and Planning IV, vol.1, Brebbia C. A. (ed.), WIT Press, Southampton, pp. 465-474, 2009.

[11] Russo F. \& Chilà G., Dynamic approaches to demand model in evacuation conditions. Proc. of Urban Transport XVI, Urban Transport and the Environment in the 21st century, Brebbia C. A. (ed.), WIT Press, Southampton, pp. 303-312, 2010.

[12] Russo F. \& Chilà G., A sequential dynamic choice model to simulate demand in evacuation conditions. Proc. of Seventh International Conference on Computer Simulation in Risk Analysis and Hazard Mitigation, Brebbia C. A. (ed.), WIT Press, Southampton, 2010.

[13] Vitetta A., Musolino G. \& Marcianò F.A., Safety of users in road evacuation: Supply and demand-supply interaction models for users. Proc. of Urban Transport XIII, Urban Transport and the Environment in the 21st century, Brebbia C. A. (ed.), WIT Press, Southampton, pp. 783-792, 2007.

[14] Vitetta A., Musolino G. \& Marcianò F. A., Safety of users in road evacuation: calibration of cost functions and simulation. Proc. of Urban Transport XIV, Urban Transport and the Environment in the 21st century, Brebbia C. A. (ed.), WIT Press, Southampton, pp. 715-725, 2008.

[15] Vitetta A., Musolino G. \& Marcianò F.A., Safety of users in road evacuation: Modelling and DSS for transport supply and supply-demand interaction. Proc. of Sustainable Development and Planning IV, vol.1, Brebbia C. A. (ed.), WIT Press, Southampton, pp. 475-484, 2009.

[16] Vitetta A., Musolino G. \& Marcianò F. A., A system of models for signal setting design of a signalized road network in evacuation conditions. Proc. of Urban Transport XVI, Urban Transport and the Environment in the 21st century, Brebbia C. A. (ed.), WIT Press, Southampton, pp. 313-323, 2010.

[17] Marcianò F.A., Musolino G. \& Vitetta A., Signal setting design on a road network: application of a system of models in evacuation conditions. Proc. of Seventh International Conference on Computer Simulation in Risk Analysis and Hazard Mitigation, Brebbia C. A. (ed.), WIT Press, Southampton, 2010.

[18] Vitetta A., Quattrone A. \& Polimeni A., Safety of users in road evacuation: design of path choice models for emergency vehicles. Proc. of Urban Transport XIII, Urban Transport and the Environment in the 21st century, Brebbia C. A. (ed.), WIT Press, Southampton, pp. 803-812, 2007.

[19] Vitetta A., Quattrone A. \& Polimeni A., Safety of users in road evacuation: algorithms for path design of emergency vehicles, Proc. of Urban 
Transport XIV, Urban Transport and the Environment in the 21st century, Brebbia C. A. (ed.), WIT Press, Southampton, pp. 727-737, 2008.

[20] Vitetta A., Quattrone A. \& Polimeni A., Safety of users in road evacuation: Modelling and DSS for paths design of emergency vehicles, Proc. of Sustainable Development and Planning IV, vol.1, Brebbia C. A. (ed.), WIT Press, Southampton, pp. 485-495, 2009.

[21] Polimeni A., Quattrone A. \& Vitetta A., A tool for tracing emergency vehicles during evacuation, Proc. of Urban Transport XVI, Urban Transport and the Environment in the 21st century, Brebbia C. A. (ed.), WIT Press, Southampton, pp. 325-333, 2010

[22] Polimeni A., Quattrone A. \& Vitetta A., An approach to design vehicle routes in evacuation conditions, Proc. of Seventh International Conference on Computer Simulation in Risk Analysis and Hazard Mitigation, Brebbia C. A. (ed.), WIT Press, Southampton, 2010.

[23] Vitetta A. \& Assumma V., Safety of users in road evacuation: Simulation of Refuge's Area for Users, Proc. of Urban Transport XIII, Urban Transport and the Environment in the 21st century, Brebbia C. A. (ed.), WIT Press, Southampton, pp. 793-802, 2007.

[24] Coelli, T., Rao \& D. S. P., Battese, G. E. An Introduction to Efficiency and Productivity Analysis, Kluwer Academic Publishers, 1998. http://www.treasury.govt.nz/workingpapers/99-5.htm (February 2009).

[25] Farrell, M. J., "The measurement of productive efficiency", Journal of the Royal Statistical Society A 120 pp. 253-281, 1957.

[26] Charnes, A., Cooper, W.W. \& Rhodes E., Measuring the efficiency of decision making units, European Journal of Operational Research 2 pp. 429-444, 1978.

[27] Banker R.D., Charnes A. \& Cooper W.W., Some models for estimating technical and scale inefficiencies in data envelopment analysis, Management Science 30, pp. 1078-1092, 1984.

[28] Cooper, W.W., Seiford, L.M. \& Tone, K., Data Envelopment Analysis, Kluwer Academic Publisher, Boston, USA, 2000.

[29] Tavaresa, G., A bibliography of data envelopment analysis (1978-2001), Rutcor Research Report, Rutgers University, Center for Operations Research, New Jersey, USA, 2002.

[30] Nozick, L. K., Borderas H. \& Meyburg A. H., Evaluation of travel demand measures and programs: A data envelopment analysis approach, Transportation Research Part A: Policy and Practice 32(5), pp 331-343, 1998.

[31] Odeck, J., Congestion, ownership, region of operation, and scale: Their impact on bus operator performance in Norway, Socio-Economic Planning Sciences 40, pp 52-69, 2006.

[32] Cullinane K. P. B., Wang T., Song D. \& Ji P., The technical efficiency of container ports: Comparing data envelopment analysis and stochastic frontier analysis, Transportation Research Part A: Policy and Practice 40, pp. 354-374, 2006. 
[33] Lupi M. \& Danesi A., Valutazione globale delle performance aeroportuali: applicazione della Data Envelopment Analysis (DEA) agli aeroporti italiani, in Linee guida per la programmazione dello sviluppo degli aeroporti regionali. Lupi M. (ed.), FrancoAngeli, Milan, Italy. pp. 181-210, 2007.

[34] Cook W. D. \& Green, R. H., "Project prioritization: a resource-constrained data envelopment analysis approach", Socio-Economic Planning Sciences, 34, pp. 85-99, 2000.

[35] Tsamboulas D. \& Mikroudis G., EFECT: evaluation framework of environmental impacts and costs of transport initiatives, Transportation Research Part D: transport and environment 5, pp. 283-303, 2000.

[36] Bernroider E.W.N. \& Stix V., Profile distance method: a multi-attribute decision making approach for information system investments. Decision Support Systems 42, pp 988-998, 2006.

[37] Lahdelma R. \& Salminen P., Stochastic multicriteria acceptability analysis using the data envelopment model, European Journal of Operational Research 170, pp. 241-252, 2006.

[38] Cullinane K. P. B. \& Wang T., Data Envelopment Analysis (DEA) and Improving Container Port Efficiency, in Brooks M.R. and Cullinane K.P.B. (eds) Port Governance and Performance, Research in Transportation Economics, Vol. 17, Elsevier: London, pp. 517-566, 2007.

[39] Charnes, A. Clark, C. T. Cooper, W. W. \& Golany, B., A Developmental Study of Data Envelopment Analysis in Measuring the Efficiency of Maintenance Units in the U.S. Air Forces, Annals of Operation Research, 2, pp. 95-112, 1985. 